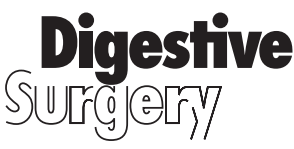

\author{
Akkermans, L.M.A. 234 \\ Besselink, M.G.H. 234 \\ Borel Rinkes, I.H.M. 282 \\ Bosma, P.J. 222 \\ Buskens, C.J. 222 \\ Chamuleau, R.A.F.M. 254 \\ de Boer, M.T. 265 \\ de Jong, K.P. 245 \\ de Noo, M.E. 276 \\ Deurholt, T. 254 \\ Gooszen, H.G. 234 \\ Gouma, D.J. 221 \\ Hendriks, H.G.D. 265 \\ Hoekstra, R. 254 \\ IJzermans, J.N.M. 245
}

\author{
Liefers, G.J. 276 \\ Los, M. 282 \\ Marsman, W.A. 222 \\ Molenaar, I.Q. 265 \\ Porte, R.J. 265 \\ Poyck, P.P.C. 254 \\ Ruers, T.J.M. 245 \\ Slooff, M.J.H. 265 \\ Timmerman, H.M. 234 \\ Tollenaar, R.A.E.M. 276 \\ van de Kerkhove, M.P. 254 \\ van Gulik, T.M. 254 \\ van Lanschot, J.J.B. 221, 222 \\ van Minnen, L.P. 234 \\ Voest, E.E. 282
}

\title{
Subject Index Vol. 22, No. 4, 2005
}

Acute liver failure 254

- pancreatitis 234

Antiangiogenesis, gastrointestinal tumors 282

Antibiotic prophylaxis, surgical patients 234

Antifibrinolytics, liver transplantation 265

Bacterial translocation 234

Bioartificial liver 254

Blood loss 265

- transfusion 265

Cancer gene therapy, strategies 222

Colorectal cancer 276

- -, prognosis 276

Esophageal cancer, optimizing gene therapy 222
Gastrointestinal cancer 282

Gene delivery methods 222

- therapy, esophageal cancer 222

Genomics 276

Hemostasis, liver transplantation 265

Hepatocytes 254

Immune system, infection prevention 234

Liver transplantation 254, 265

- tumors 245

Minimal residual disease, colorectal cancer 276

Probiotics 234

Proteomics 276

Radiofrequency, liver tumors 245

Vascular endothelial growth factor, gastrointestinal oncology 282 